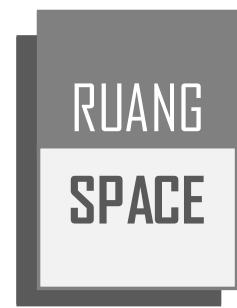

\title{
POLA TATA RUANG KAMPUNG ADAT WOLOGAI DI DESA WOLOGAI TENGAH KABUPATEN ENDE
}

\author{
Oleh: Vinsensius Rikardus Edo ${ }^{1}$
}

\begin{abstract}
This article aims at exploring the characteristic of spatial pattern of Wologai Settlement, a unique traditional neighborhood of Ende-Flores. It studies the natural setting; customs and traditions; as well as spatial uses and functions. These elements are considered as encompassing elements conferring to spatial traits that characterize this Wologai Settlement. This research is a qualitative research and mainly uses a field survey method for its data collection. The article has three main parts. The first explains the existing Kampung Wologai and its unique physical natural setting. The second describes fundamental physical and non-physical elements determining the spatial formation of Wologai Settlement. And lastly, the third part presents discussion over intrinsic attributes imbedded within Wologai's spatial pattern. This study construes that the prominent circular spatial pattern of Kampung Wologai, on the one hand symbolizes a strong connection with a unique concept of kinship that creates a resilient society. And it is also a product of adaptation to terraced natural topography as well as a customary concept of orienting its neighborhood toward a mountain as a sacred natural feature, on the other.
\end{abstract}

Keywords: Wologai settlement, spatial pattern, space, customs

\begin{abstract}
Abstrak
Artikel ini bertujuan untuk membahas keberadaan Kampung Adat Wologai sebagai salah satu kampung adat di Kabupaten Ende yang memiliki keunikan. Keunikan dapat dilihat dari pola ruang, karakteristik ruang yang bertingkat-tingkat, elemen dan pemanfaatan ruang berdasarkan fungsinya, serta masih mempertahankan adat istiadat hingga saat ini. Penelitian ini merupakan penelitian kualitatif dan menggunakan teknik field research atau penelitian lapangan. Pendekatanfield research dipilih karena pendekatan ini lebih cenderung kepada pengamatan mendalam di lapangan terhadap sebuah objek. Pada bagian pertama artikel ini membahas tentang keberadaan dan keunikan fisik ruang Kampung Wologai untuk diteliti. Bagian kedua menjelaskan tentang elemen pembentuk ruang-ruang yang ada di Kampung Adat Wologai. Bagian ketiga artikel ini menerangkan hasil dan pembahasan. Kehidupan masyarakat di Kampung Adat Wologai masih bersifat tradisional dan sangat sederhana. Pola tata ruang merupakan bentuk atau wujud pemanfaatan ruang berdasarkan elemen-elemen dan fungsinya. Pola tata ruang Kampung Adat Wologai dapat dilihat dari pola/bentuk, elemen-elemen penyusun, yang ada di Kampung Wologai. Pola penataan ruang di Kampung Adat Wologai berbentuk melingkar dan memiliki karakteristik bertingkat-tingkat. Hal ini menjadi sebuah fenomena yang unik untuk dieksplor. Permukiman Kampung Adat Wologai berorientasi ke Gunung Lepembusu yang merupakan gunung sakral yang dipercayai oleh masyarakat Wologai sebagai tempat lahirnya manusia pertama dan leluhur masyarakat Wologai. Pola tata ruang Kampung Adat Wologai berbentuk melingkar dibuat berdasarkan hubungan kekerabatan, dan bertujuan untuk membentuk interaksi dan persaudaraan yang kuat dalam kehidupan bermasyarakat.
\end{abstract}

Kata kunci: kampung adat, Wologai, pola, ruang, adat istiadat

1 Program Studi Magister Arsitektur Universitas Udayana

Email: rikardulfia@gmail.com 


\section{Pendahuluan}

Indonesia memiliki beragam tipe permukiman etnik yang tersebar di seluruh Indonesia, dan menjadi salah satu kekayaan pengetahuan arsitektur yang harus digali dipahami untuk pengkayaan pengetahuan kearsitekturan. Salah satu permukiman etnik yang memiliki keunikan adalah Kampung Adat Wologai di Kabupaten Ende Flores. Kampung Adat Wologai adalah salah satu permukiman tradisional masyarakat Wologai yang masih memiliki pola permukiaman yang berbasis pada sistem kepercayaan masyarakat setempat.

Kampung Adat Wologai terletak di Desa Wologai Tengah, Kecamatan Detusoko Kabupaten Ende kira-kira $40 \mathrm{Km}$ arah timur Kota Ende. Perkampungan adat ini merupakan salah satu dari 24 komunitas adat Suku Lio yang berada di sekitar Kawasan Taman Nasional Kelimutu, dengan budayanya yang luhur, dan sangat kental dengan perilaku agraris, religius, sekaligus magis dengan kedekatannya yang kuat pada alam. Dengan tatanan ruang yang masih berpegang pada kebudayaan lama dan nilai asli yang ada menjadikan perlunya penelitian terhadap pola tata ruang di Kampung Adat Wologai.

Menurut kepercayaan masyarakat, Wologai merupakan bukit berumput. "Wolo", (pegunungan/bukit), "Gai" (sejenis rumput). Struktur kemasyarakatan berpola matrilineal dimana garis keturunan dari ibu memegang peranan penting dalam pengaturan keluarga hingga masyarakat. Namun demikian, mereka bukanlah kelompok masyarakat yang matriarki atau kekuasaan yang dipegang oleh garis keturunan langsung seorang perempuan. Kaum pria di Kampung Adat Wologai masih memegang peranan kepemimpinan dalam keluarga dan masyarakat.

Masyarakat Kampung Adat Wologai meyakini nenek moyangnya berasal dari Gunung Lepembusu. Setiap rumah di Kampung Adat Wologai menghadap ke arah bangunan yang difungsikan sebagai tempat berkumpulnya para ketua adat. Dalam Kampung Adat Wologai terdapat pelataran yaitu berupa batu ceper yang berada di tengah permukiman yang berfungsi sebagai tempat meletakkan persembahan kepada leluhur dan sang pencipta. Kampung Adat Wologai dibangun berdasarkan keseimbangan interaksi terhadap alam lingkungan dan hubungannya dengan pencipta alam semesta yang dipercayanya. Kepercayaan mereka berdasarkan orientasi gunung-laut dan matahari terbit-tenggelam.

Kampung Adat Wologai merupakan salah satu kampung adat yang sudah sangat lama keberadaanya dan memiliki keunikan tersendiri, dari penataan ruang sampai dengan pemanfaatan ruang. Hal ini terlihat jelas dengan adanya pembagian ruang yang berbedabeda dan sesuai dengan fungsinya masing-masing. Ruang untuk rumah para suku, ruang untuk pemakaman, dan ruang untuk musyawarah kepala adat serta ruang sesajian untuk para leluhur. Ruang untuk rumah para suku terdiri dari bangunan rumah adat. Ruang untuk pemakaman yaitu terdiri dari susunan batu asli yang disusun secara rapi mengelilingi Keda dan Kanga.

Tradisi dan upacara-upacara yang sakral dan bentuk ruang kampung yang memiliki daya tarik tersendiri menjadikan Kampung Adat Wologai didatangi oleh para wisatawan domestik dan asing. Hal ini tidak terlepas dari nilai luhur yang terus dijalankan dan keramahan masyarakat dalam menerima tamu. Beragam potensi dan kerajinan tangan yang ada di 
Kampung Adat Wologai juga menjadi daya tarik bagi para wisatawan untuk berkunjung ke Kampung Adat Wologai.

\section{Metode Penelitian}

Penelitian ini berfokus pada Kampung Adat Wologai. Kampung Adat Wologai terletak di Desa Wologai Tengah, Kecamatan Detusoko Kabupaten Ende, kira-kira 40 km arah timur kota Ende, dengan jarak tempuh waktu 1-1.5 jam dari Kota Ende. Penelitian ini merupakan penelitian kualitatif, menggunakan teknik field research atau penelitian lapangan. Pendekatan field research dipilih karena pendekatan ini lebih cenderung kepada pengamatan mendalam di lapangan terhadap sebuah objek. Pengamatan tersebut dilakukan di Kampung Adat Wologai. Permasalahan dan pertanyaan terhadap sebuah objek akan mudah ditemukan dengan observasi langsung di Kampung Adat Wologai.

Dalam penelitian kualitatif data primer didapatkan langsung melalui observasi lapangan, dan melakukan interview/wawancara, hingga menyebarkan kuesioner, sedangkan untuk data sekunder didapatkan melalui telaah dokumen. Penelitian kualitatif secara khusus berorientasi pada observasi, penemuan, dan logika induktif. Dikatakan induktif karena dalam mengumpulkan data seorang peneliti tidak memaksakan diri untuk membatasi penelitian guna menerima atau menolak dugaan-dugaan melainkan memahami situasi (make sense of the situation) sesuai dengan bagaimana situasi tersebut menampilkan diri (Gunawan, 2015).

\section{Pola Tata Ruang Permukiman}

Mbete dkk, menjelaskan bahwa pola permukiman Kampung Adat Suku Ende-Lio selalu dilihat dalam hubungan dengan tempat asal manusia pertama Suku Ende Lio yaitu Gunung Lepembusu. Berdasarkan pertimbangan inilah ujung pemukiman adat Suku Lio selalu mengarah ke Gunung Lepembusu dan arah berlawanan mengarah ke daerah paling rendah yaitu lautan. Hal ini sesuai dengan kosmologi masyarakat Ende-Lio kaitannya dalam pemukiman yaitu ulu (kepala) dan eko (hilir) dan diantara terdapat puse (pusat). Ulu dihubungkan dengan matahari terbit atau ke arah Gunung Lepembusu sedangkan $e k o$ kearah matahari terbenam atau berlawanan dengan gunung tempat asal usul nenek moyang suku Ende Lio (Achmad, 2014:8). Pola permukiman Kampung Adat Suku Ende-Lio, dapat dilihat pada Gambar 1.

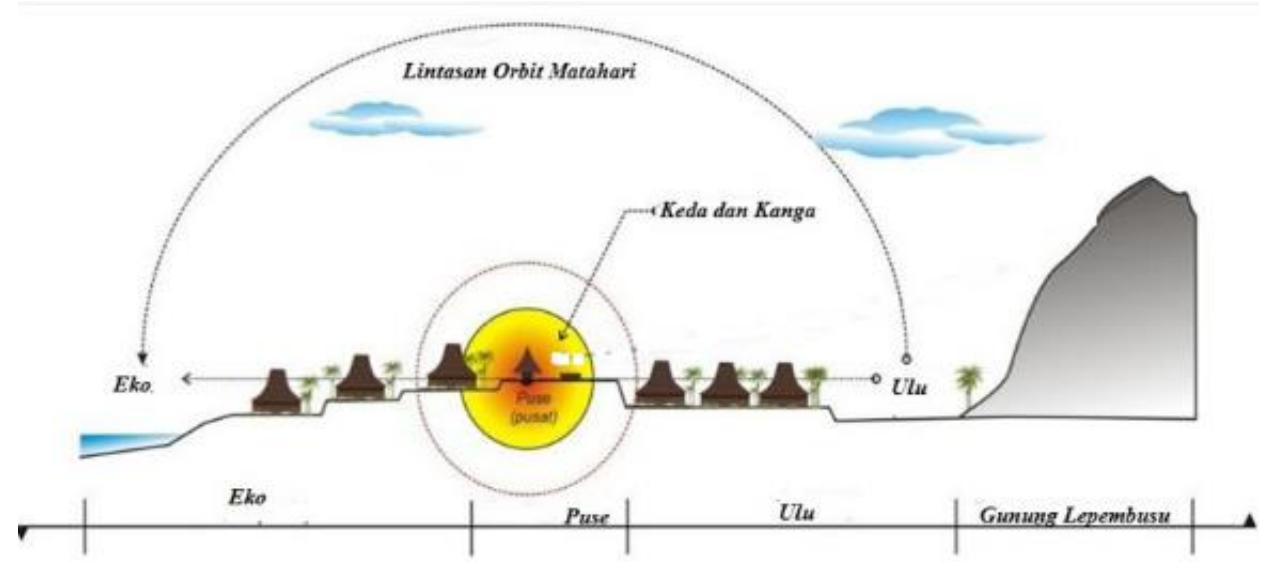

Gambar 1. Orientasi Gunung dan Laut

Sumber: Dimodifikasi dari Achmad (2014) 
Hubungan kepercayaan gunung dan laut dengan kampung terlihat pada garis linear dimana puse atau pusat merupakan Kampung Adat Wologai. Struktur garis linear pada kepercayaan gunung, kampung dan laut diibaratkan seperti seorang manusia. Pengertian tersebut ada pada ungkapan adat yaitu uzhu du mutu hai kenda ia yang artinya kepala manusia bersandar di Gunung Lepembusu, dan kaki bertumpuk pada laut dan di tengah-tengah antara gunung dan laut adalah tubuh manusia yaitu Kampung Adat Wologai. Ungkapan adat tersebut memiliki makna bahwa manusia yang sudah meninggal dikuburkan bagian kepalanya harus menghadap gunung dan kakinya menghadap laut.

Kampung Adat Wologai memilki 22 bangunan dalam areal kampung terdiri dari 18 buah rumah adat, 4 bangunan lain dan 1 buah tempat penyimpanan benda-benda adat dan tulang nenek moyang yaitu Bhale yang berada di samping tempat hunian utama para Mosalaki yaitu Keda dan sebagai tempat untuk melangsungkan seremonial adat. Di Kampung Adat Wologai rumah adat dibangun dalam 1 lokasi dimana lokasi tersebut dibatasi dengan fondasi berupa susunan batu-batu, tidak ada dan tidak boleh dibangun rumah penduduk dalam lokasi tersebut, dibangun dengan formasi tersusun melingkar, satu rumah adat induk berada ditengah dan 18 buah rumah adat dibangun menghadap rumah adat induk menggambarkan kepatuhan terhadap pemimpin. Rumah adat induk ini menghadap ke Gunung Lepembusu, sangat jelas terlihat dari arah pintu rumah dan tangga naik menuju rumah induk.

Orientasi bangunan dalam Kampung Adat Wologai dapat dilihat berdasarkan orientasi bukaan pintu utama dan arah atap. Mayoritas bukaan pintu utama dari massa bangunan terlihat jelas bahwa mengarah pada ruang terbuka yang sering digunakan untuk aktivitas dan sirkulasi spiritual yakni mengarah Tubu Musu, sebagai titik sentral (central point). Tubu Musu sebagai ruang dan tempat pelaksanaan aktivitas spiritual berkaitan dengan kepercayaan masyarakat terkait hubungan dengan leluhur dengan sang pencipta. Leluhur yang berasal dari Gunung Lepembusu dikubur mengelilingi pelataran aktivitas spiritual yaitu Tubu Musu.

Setiap rumah adat saling berhadapan bermaksud: saling mendukung dan menjaga tempat sakral yaitu Keda, Tubu Musu dan Kanga. Tempat sakral berupa Keda, Tubu Musu dan Kanga merupakan ruang sakral yang sangat dijunjung tinggi oleh masyarakat Kampung Adat Wologai dimana para leluhur mereka dikuburkan mengelilingi Keda, Tubu Musu dan Kanga dan dikuburkan dengan menggunakan batuan megalitik.

Kampung Adat Wologai dalam penataan ruangnya memiliki fungsi yang bersifat sakral maupun profan. Fungsi sakral yang berkaitan dengan aktifitas upacara-upacara baik dalam skala besar ataupun kecil seperti, upacara pati ka (memberi makan kepada leluhur), pernikahan, kematian dan upacara peresmian rumah adat. Sedangkan yang bersifat profan seperti aktivitas masyarakat dalam melakukan interaksi dengan sesama penghuni Kampung Adat Wologai. Tata ruang secara sakral dilihat dari peletakan batuan megalitik yang berada di tengah Kampung yaitu Kanga dan Tubu musu dan juga berhubungan dengan media kubur di area kampung. Bangunan megalitik kubur ini biasanya diletakkan di depan rumah dari suku yang bersangkutan karena penempatan bangunan megalitik di depan rumah memberikan aura positif dan melindungi keluarga maupun suku dari ancaman bahaya. 
Sesuai dengan penjelasan orientasi bangunan Kampung Adat Wologai, maka dapat dilihat pada Gambar 2.

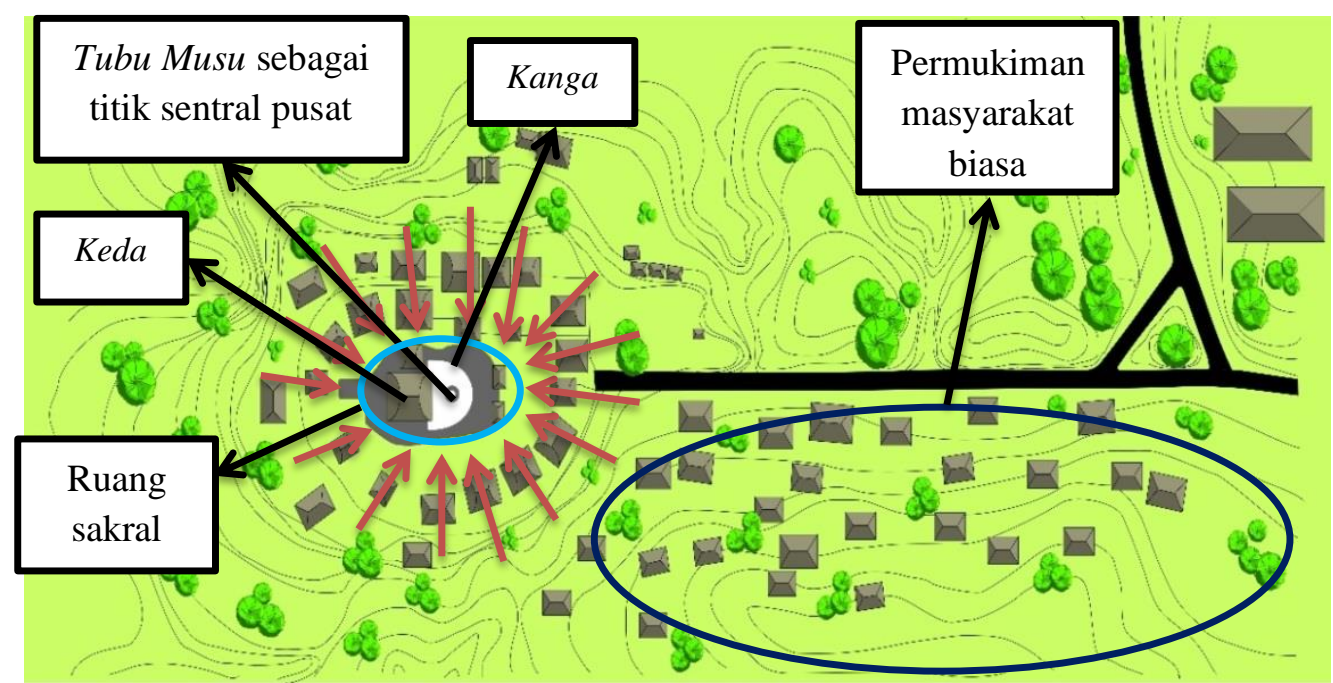

Gambar 2. Arah Orientasi Bangunan di Kampung Adat Wologai

Sumber: Dimodifikasi dari Achmad (2014)

Rumah-rumah yang ada berada di sekitar kampung adat merupakan rumah dari keturunan masyarakat adat Wologai. Menurut Bapak Pius Ndawi sebagai Mosalaki Pu'u, Bapak Paulus Lengga yang mewakili Mosalaki Ria Bewa, dan Bapak Markus Mau sebagai Mosalaki Pidhi Wiwi Lapi Lema, anak yang sudah gadis tinggal di luar rumah lingkaran kampung. Sedangkan masyarakat yang tinggal dalam rumah adat hanya mereka yang bertugas pada saat upacara adat. Tidak ada keturunan dari luar masyarakat adat yang tinggal di lingkaran luar kampung adat. Tanah adat yang terdapat di Kampung Adat Wologai tidak boleh dijual belikan.

Tata ruang secara profan bisa dilihat dari orientasi rumah adat bagaimana mereka mengutamakan komunikasi dan keterbukaan secara sederhana tapi tegas terlihat dari pembentukan tata ruang dan penempatan teras semi terbuka disisi muka rumah yang menghadap ke ruang tengah publik. Model teras semi terbuka dapat dilihat pada Gambar 3 .

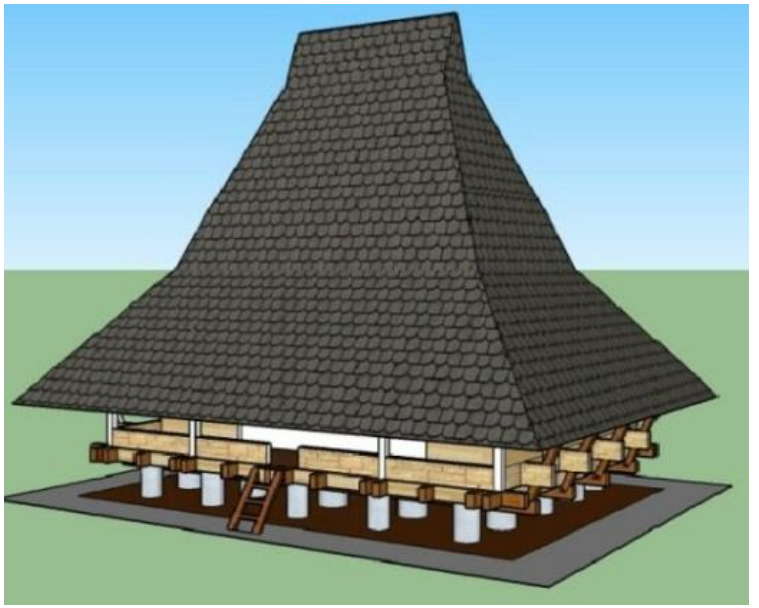

Gambar 3. Teras semi terbuka yang menghadap ke ruang tengah publik Kampung Adat Wologai Sumber: Dimodifikasi dari Achmad (2017) 


\section{Pola Keruangan Bangunan Rumah Tinggal (Sa’O) Suku}

$\mathrm{Sa}$ 'O Suku merupakan tempat tinggal para Mosalaki beserta sukunya. $\mathrm{Sa}$ 'O suku sebenarnya bukan hanya sekedar tempat tinggal saja tetapi mempunyai makna yang teramat dalam, yaitu $\mathrm{Sa}$ 'O diibaratkan sebagai perut ibu dan masyarakat yang tinggal di dalam $\mathrm{Sa}$ 'O sama seperti masyarakat tinggal di dalam perut seorang ibu. $\mathrm{Sa} O$ suku adalah tempat hidup dan berinteraksi komunitas masyarakat Lio, karena pada prinsip keseimbangan antar manusia dan manusia serta keseimbangan manusia dengan alam. Prinsip keseimbangan yang dimaksud adalah interaksi yang baik dan adil antara sesama masyarakat dan adanya upaya menjaga dan melestarikan alam, karena alam memberikan kehidupan bagi masyarakat Kampung Adat Wologai.

Setiap suku mempunyai bentuk bangunan rumah adat yang sama akan tetapi memiliki ciri khas yang berbeda seperti ukiran yang ada pada tiang kayu bangunannya. Proses untuk membangun rumah adat tidak boleh sembarangan, akan tetapi perlu didahului dengan ritual adat naka wisu. Ritual tersebut adalah aturan memotong pohon di hutan untuk digunakan sebagai tiang penyangga rumah. Ritualnya harus dilakukan pada pukul 12 malam, dengan terlebih dahulu upacara menyembelih seekor ayam.

Makna rumah adat $\left(\mathrm{Sa} \mathrm{O}^{\mathrm{O}}\right)$ suku di Kampung Adat Wologai yaitu rumah adalah perut ibu ( $\mathrm{Sa}$ 'O adalah tuka ine). Dimana penjelasan maknanya rumah adalah perut ibu dan masyarakat tinggal di dalam rumah berarti di dalam perut seorang ibu. Secara terperinci yaitu tangga: kaki ine, teras: dua telapak tangan, masuk rumah sama dengan masuk dalam perut. Bagian dalam rumah terdapat one (ruang tengah), dhembi (dapur), lulu (kamar tidur) dan lore/gare meo (kamar tidur anak-anak umur 5-6 tahun tempat tidurnya di atas loteng). Pola keruangan $\mathrm{Sa}$ 'O suku Kampung Adat Wologai dilihat pada Gambar 4.

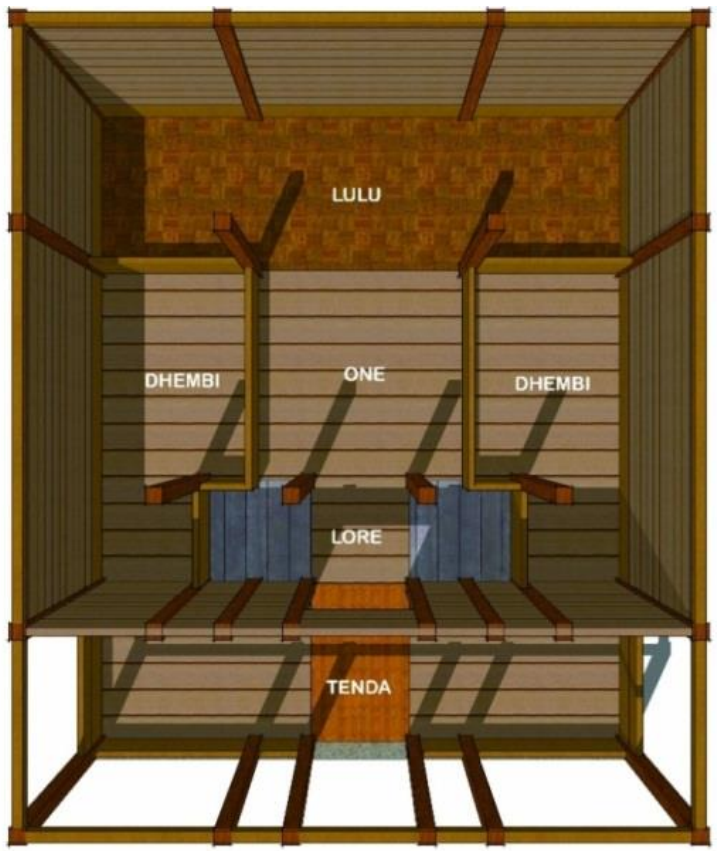

Gambar 4. Ruangan Dalam Sa’O Suku

di Kampung Adat Wologai

Sumber: Dimodifikasi dari Achmad (2017) 


\section{Elemen Pembentuk Ruang Kampung Adat Wologai}

Elemen ruang pembentuk Kampung Adat Wologai terdiri dari Sa'O, Keda, Kanga, Tubu Musu dan Lele Lako. Hiraraki tertingginya yaitu Tubu Musu yang merupakan tempat persembahan untuk sang pencipta. Elemen penyusunan ruang dapat dilihat pada Gambar 5.

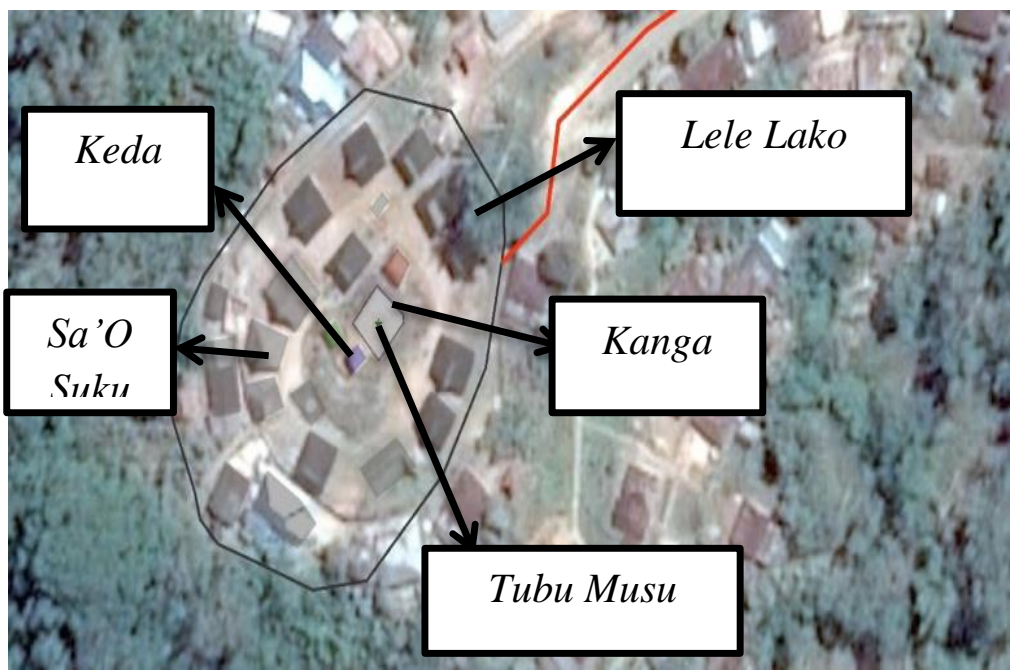

Gambar 5. Elemen Penyusunan Ruang Kampung Wologai

Sumber: Diolah dari Google-earth.com

Elemen-elemen tersebut dapat diuraikan sebagai berikut :

\section{Keda}

Keda adalah bangunan rumah dengan atap ilalang yang menjulang tinggi dan merupakan tempat dilaksanakan musyawarah adat beserta upacara-upcara adat yang dipimpin oleh Mosalaki. Keda yang posisinya berada di tengah perkampungan, yang tidak memiliki dinding dibiarkan terbuka. Keda berfungsi sebagai tempat untuk menyimpan benda-benda yang berkaitan upacara adat seperti, gendang, kepala kerbau, dll.

Keda dianggap sebagai simbol kejantanan. Proses dalam membangun Keda sama saja dengan membangun rumah adat lainya akan tetapi Keda tidak mempunyai dinding, dan letaknya menghadap ke Gunung Lepembusu. Gambar posisi Keda dan gambar Keda di Kampung Adat Wologai dapat dilihat pada Gambar 6 dan Gambar 7.

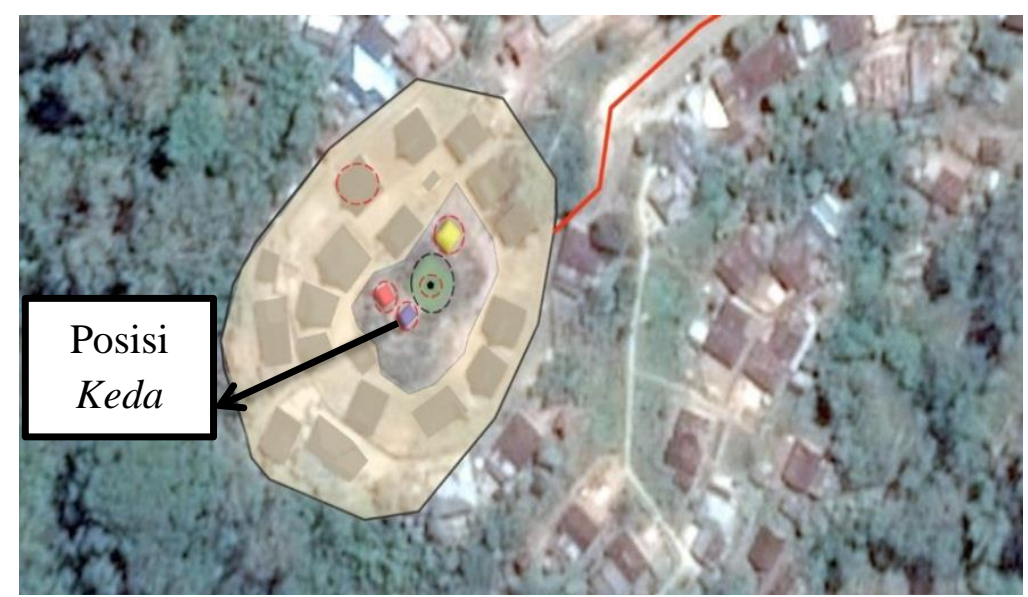

Gambar 6. Posisi Keda di Kampung Adat Wologai

Sumber: Diolah dari Google-earth.com 


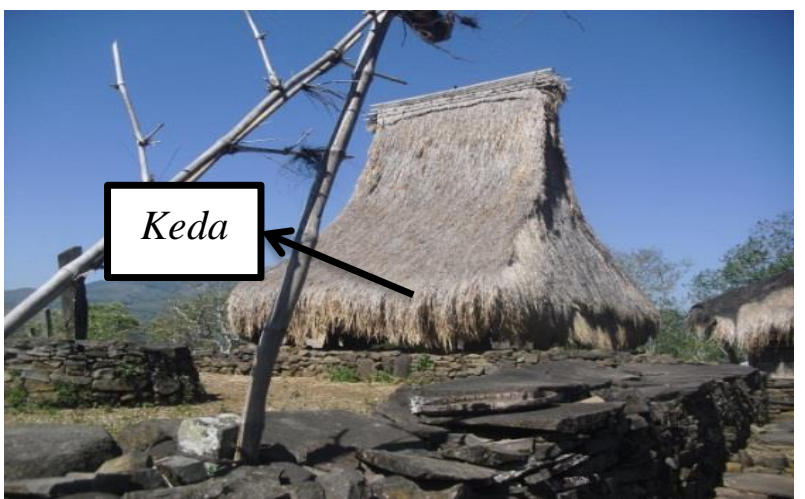

Gambar 7. Keda di Kampung Adat Wologai

Sumber: Survei lapangan, 2017

\section{Kanga}

Kanga adalah pelataran yang berbentuk melingkar dan berpagar batu di depan Keda dan Sa'O suku. Kanga di Kampung Adat Wologai berbentuk lingkaran yang mengelilingi Tubu musu, yang berupa batu lonjong yang tegak berdiri di tengah-tengah. Posisi Kanga di Kampung Adat Wologai dilihat pada Gambar 8 dan Gambar 9.

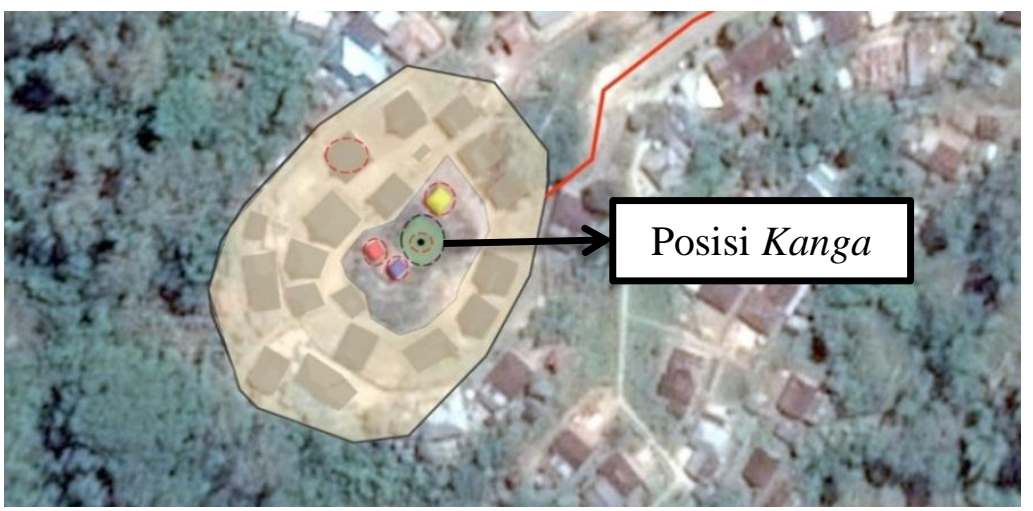

Gambar 8. Posisi Keda di Kampung Adat Wologai

Sumber: Diolah dari Google-earth.com

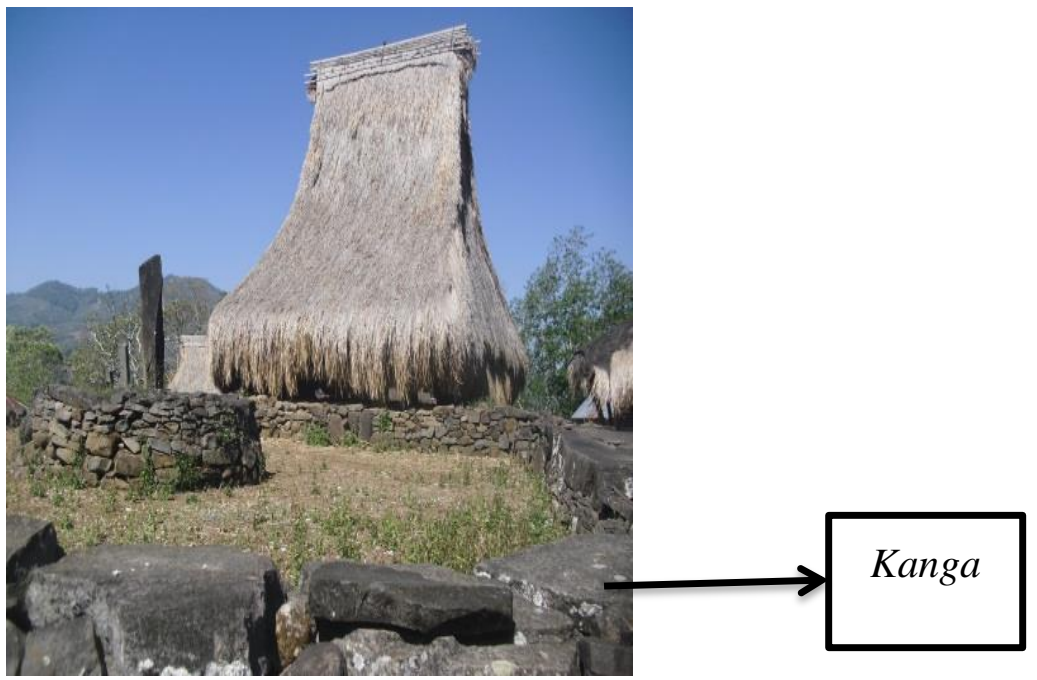

Gambar 9. Kanga di Kampung Adat Wologai

Sumber: Survei lapangan, 2017 


\section{Tubu Musu}

Tubu Musu di Kampung Adat Wologai merupakan sebuah batu lonjong yang ditancapkan ke tanah dan letaknya dibagian tengah Kanga. Di area ini Mosalaki Pu'u ini melakukan ritual-ritual yang menggunakan bahasa adat setempat untuk mempersembahkan hasil-hasil pertanian kepada leluhurnya. Posisi Tubu Musu dan model Tubu Musu dapat dilihat pada Gambar 10 dan Gambar 11.

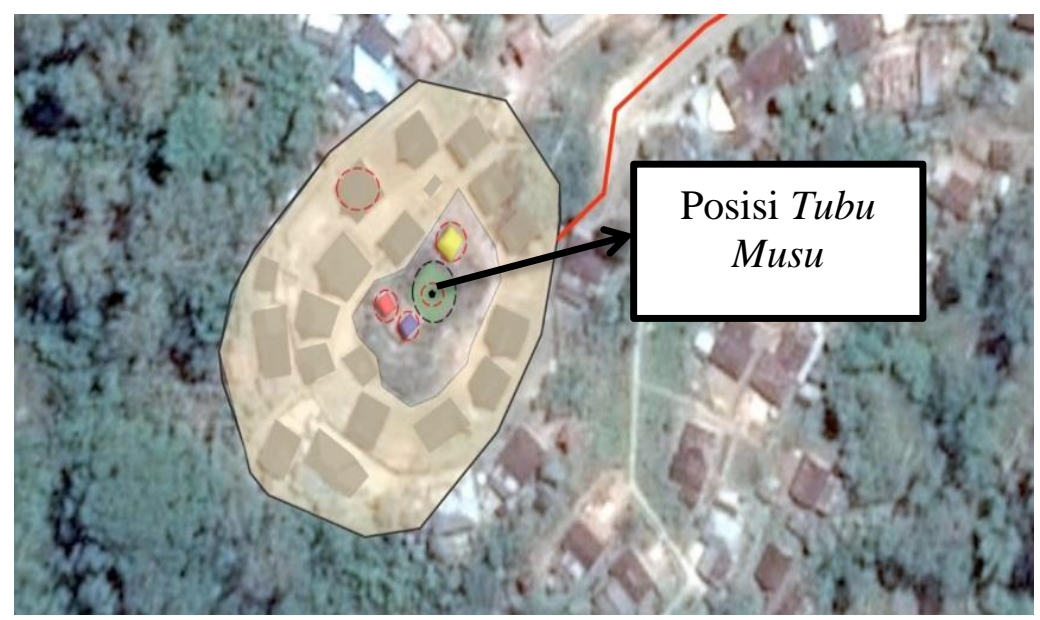

Gambar 10. Posisi Tubu Musu di Kampung Adat Wologai

Sumber: Diolah dari Google-earth.com

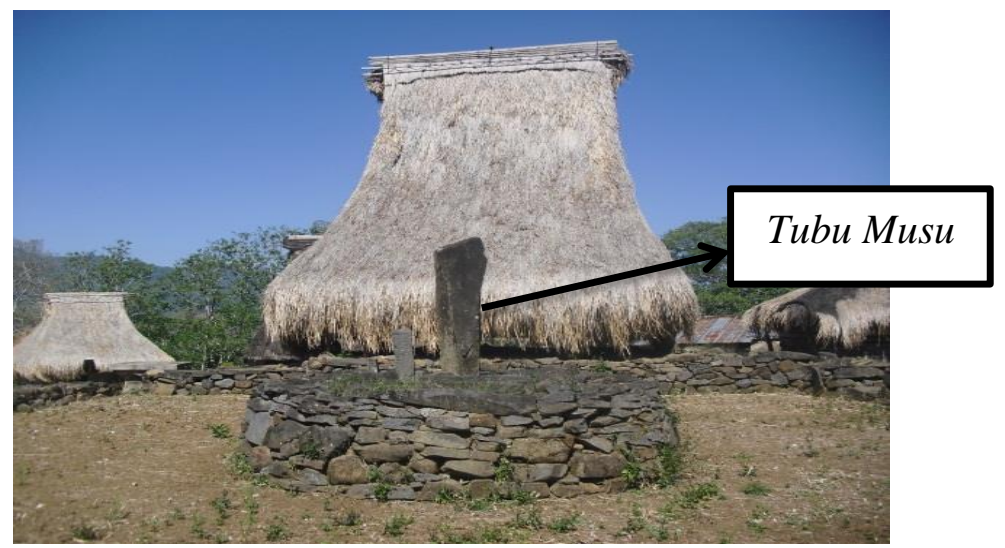

Gambar 11. Tubui Musu di Kampung Adat Wologai

Sumber: Survei lapangan, 2017

\section{4. $S a^{\prime} O$ suku}

$\mathrm{Sa} a^{\prime} \mathrm{O}$ suku merupakan tempat tinggal Mosalaki beserta sukunya. $\mathrm{Sa} O \mathrm{O}$ suku sebenarnya bukan hanya sekedar tempat tinggal saja tetapi mempunyai makna yang teramat dalam. $\mathrm{Sa}$ 'O suku adalah tempat hidup dan berinteraksi komunitas masyarakat Kampung Adat Wologai, karena pada prinsip keseimbangan antar manusia dan manusia serta keseimbangan manusia dengan alam. Posisi $\mathrm{Sa}$ 'O suku dan model $\mathrm{Sa}$ 'O dilihat pada Gambar 12 dan Gambar 13. 


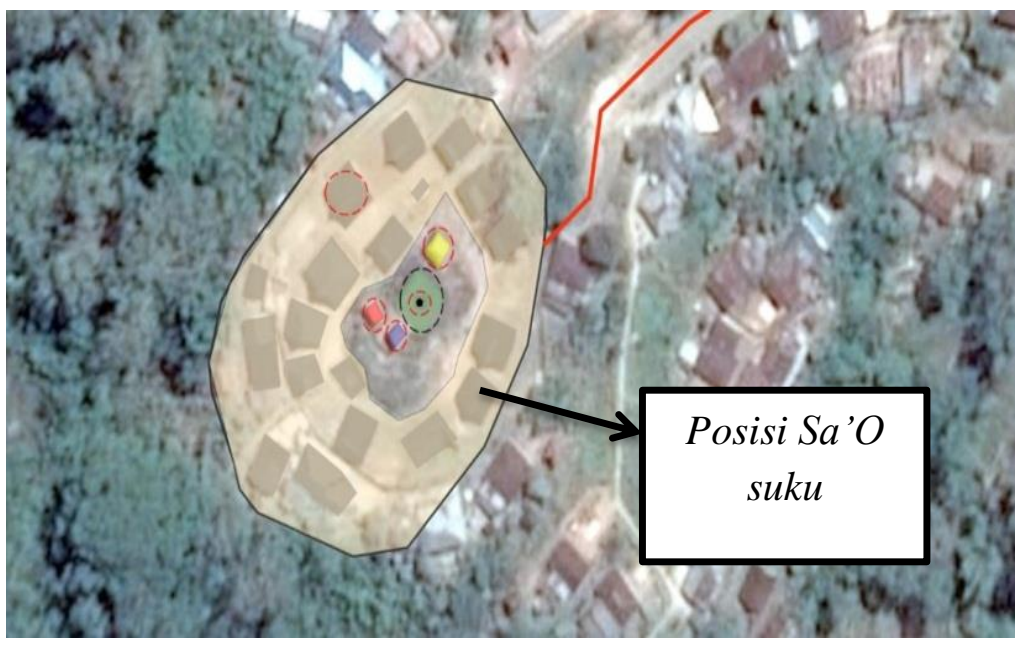

Gambar 12. Posisi Sa'O suku di Kampung Adat Wologai

Sumber: Diolah dari Google-earth.com

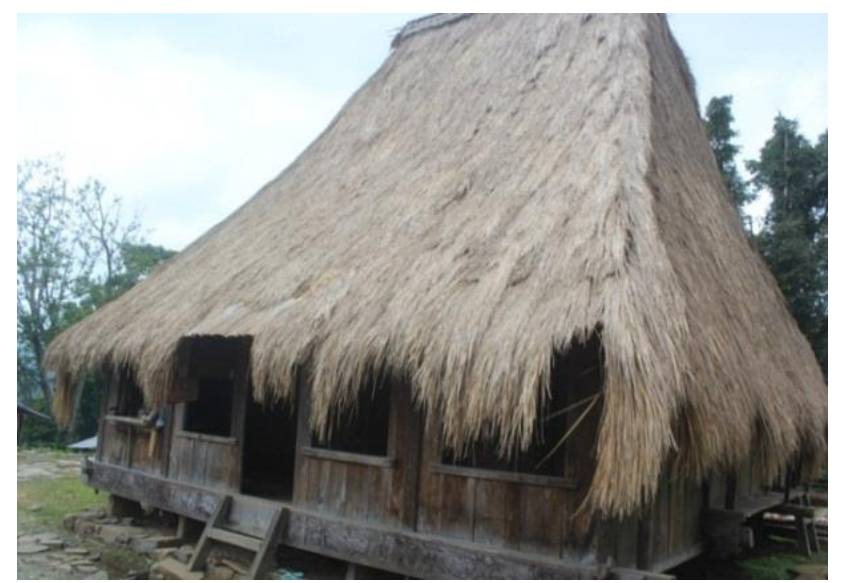

Gambar 13. Sa'O suku di Kampung Adat Wologai

Sumber: Survei lapangan, 2017

\section{Lele Lako}

Menurut Bapak Pius Ndawi sebagai Mosalaki Pu'u, di pintu masuk menuju Kampung Adat Wologai terdapat pohon beringin yang diberi nama Lele Lako. Di bawah pohon beringin ada sebuah batu yang dipercayai sebagai pelindung anjing. Anjing penjaga pintu tersebut dipercayai masyarakat setempat sebagai penjaga kampung. Tempat ini juga dijadikan tempat seremonial adat tolak bala yang dilakukan setiap tahun. Pada saat seremonial adat diberikan sesajian berupa nasi daging (are uta) dan emas (wea londa) yang dianyam dari daun lontar. Pohon beringin Lele Lako sudah ada bersamaan dengan terbentuknya Kampung Adat Wologai yang ditanam oleh nenek moyang atau leluhur masyarakat Kampung Adat Wologai. Hubungan pohon beringin dengan dengan Kampung Adat Wologai: pohon beringin Lele Lako memiliki dedaunan yang rimbun atau rindang yang berarti memberikan perlindungan kepada masyarakat Kampung Adat Wologai agar hidup damai, aman dan tentram. Posisi Lele Lako dan pohon Lele Lako dilihat pada Gambar 14 dan Gambar 15. 


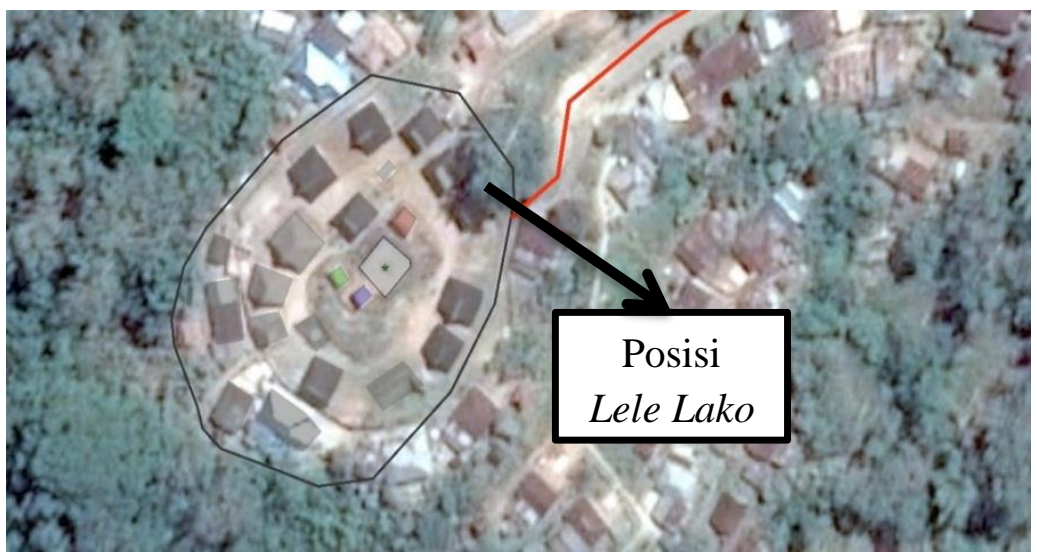

Gambar 14. Posisi Lele Lako di Kampung Adat Wologai

Sumber: Diolah dari Google-earth.com

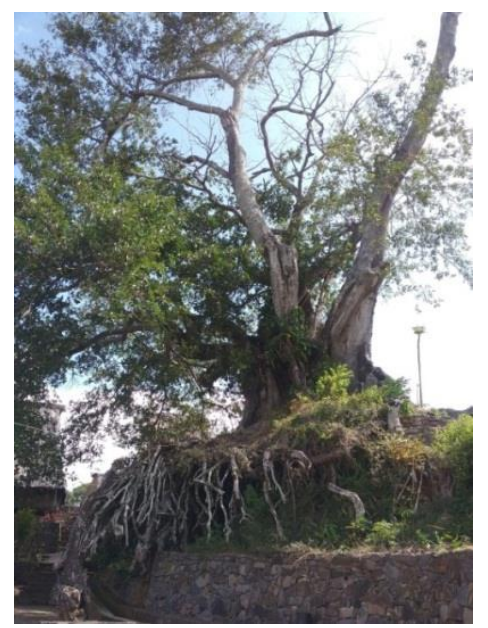

Gambar 15. Lele Lako di Kampung Adat Wologai

Sumber: Survei lapangan, 2017

\section{Hasil Dan Pembahasan}

Kampung Adat Wologai dibangun berdasarkan interaksi terhadap alam lingkungan dan hubungannya dengan pencipta alam semesta yang dipercayanya. Hal ini dapat dilihat dari upacara dan ritual yang masih dilakukan dan tetap berlaku dalam masyarakat adat termasuk acara seremonialnya. Menurut Bapak Pius Ndawi sebagai Mosalaki Pu'u, Bapak Paulus Lengga yang mewakili Mosalaki Ria Bewa, dan Bapak Markus Mau sebagai Mosalaki Pidhi Wiwi Lapi Lema mengatakan bahwa masyarakat Kampung Adat Wologai meyakini Gunung Lepembusu sebagai suatu hal yang agung, misterius, dan dapat mendatangkan ancaman jika masyarakat tidak menjaganya dengan baik.

Orientasi perkampungan Adat Wologai menghadap ke Gunung Lepembusu, hal ini disebabkan karena asal usul leluhur masyarakat Wologai berasal dari Gunung Lepembusu dan juga karena di Gunung Lepembusu adalah kampung asal atau kampung pertama masyarakat Wologai (Wologai Nua Pu'u). Struktur perkampungan adat Wologai menghadap Gunung Lepembusu, sebagai tempat lahirnya para leluhur, walaupun orientasi bangunan rumah-rumah adatnya menghadap ke ruang sakral Tubu Musu, Kanga dan Keda. Dalam setiap ritual adat yang dilakukan oleh Mosalaki, selalu mengarahkan kosentrasinya terhadap Gunung Lepembusu. 
Hubungan kepercayaan gunung dan laut dengan kampung terlihat pada garis linear dimana puse atau pusat merupakan Kampung Adat Wologai. Struktur garis linear pada kepercayaan gunung, kampung dan laut diibaratkan seperti seorang manusia. Pengertian tersebut ada pada ungkapan adat yaitu uzhu du mutu hai kenda ia yang artinya kepala manusia bersandar di Gunung Lepembusu, dan kaki bertumpuk pada laut dan di tengah-tengah antara gunung dan laut adalah tubuh manusia yaitu Kampung Adat Wologai. Ungkapan adat tersebut memiliki makna bahwa manusia yang sudah meninggal dikuburkan bagian kepalanya harus menghadap gunung dan kakinya menghadap laut.

Berdasarkan kepercayaan masyarakat Wologai terhadap Gunung Lepembusu sebagai gunung yang sakral dan sebagai kampung asal leluhur masyarakat Wologai, maka terdapat ritual adat yang dilaksanakan langsung di Gunung Lepembusu yaitu apabila terjadi bencana kekeringan, maka Mosalaki dan masyarakat adat Wologai mencari hujan di Gunung Lepembusu dengan membuat upacara adat mencari air hujan (rendu ae uja). Orientasi gunung dan laut Kampung Adat Wologai dapat dilihat pada Gambar 16.

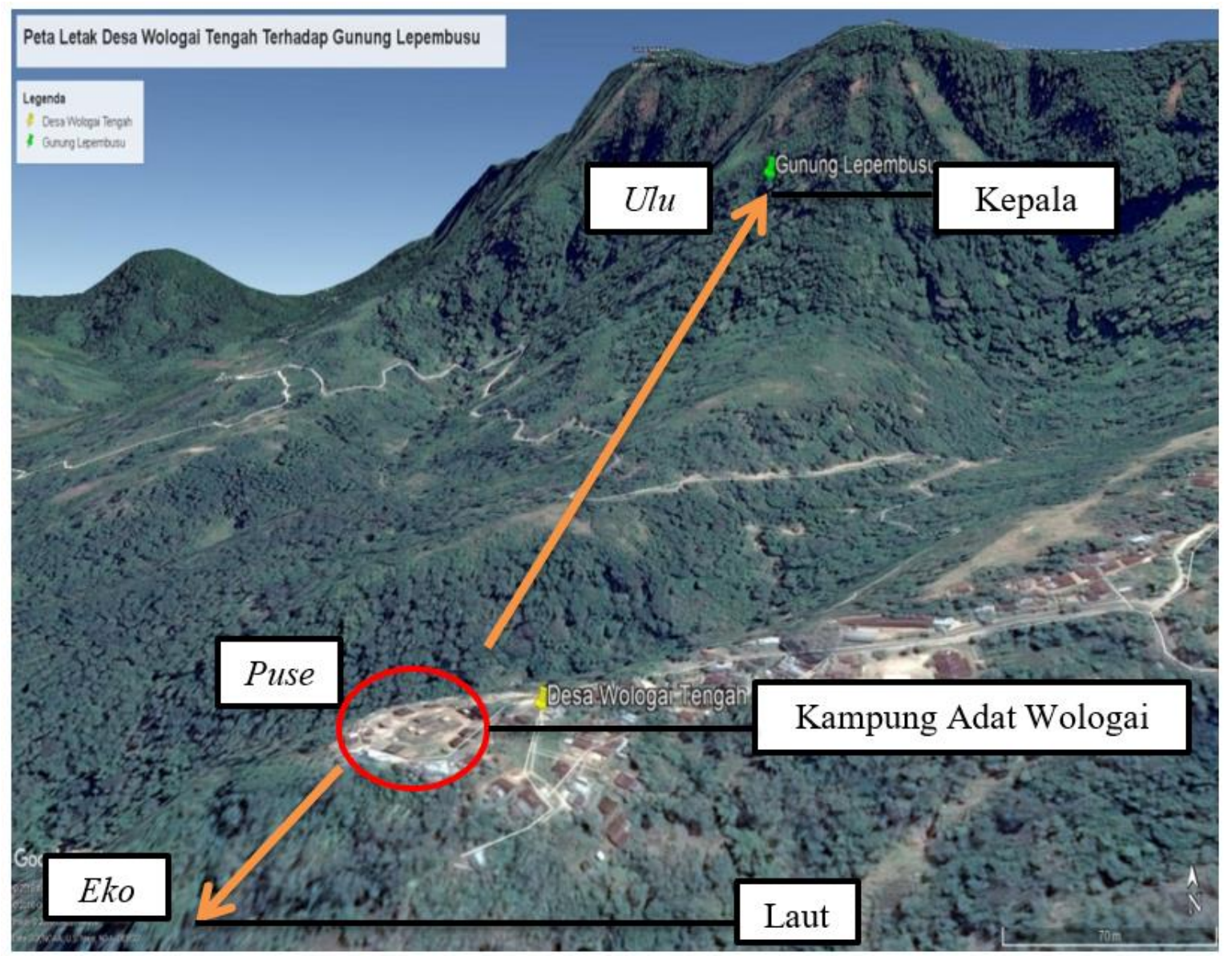

Gambar 16. Orientasi Gunung dan Laut Kampung Adat Wologai

Sumber: Diolah dari Google-earth.com 
Pola tata ruang Kampung Adat Wologai berbentuk lingkaran dengan ruang terbuka di tengah-tengahnya sebagai ruang sakral. Pola ini melingkari Tubu Musu, Keda dan Kanga sebagai pusat ruang aktivitas dan tempat pelaksanaan upacara adat dalam kampung. Hal ini sangat berpengaruh terhadap penempatan rumah-rumah Mosalaki dimana rumah-rumah Mosalaki yang terdapat di dalam kampung juga melingkar mengikuti pola tersebut. Hal ini sebagai bentuk kerjasama untuk interaksi dan saling menjaga antar sesama suku dan penghormatan kepada para leluhur dan sang pencipta yang disimboliskan dengan Tubu Musu yang berupa tiang batu yang berada di tengah-tengah ruang terbuka.

Karakteristik ruang yang bertingkat-tingkat semakin keatas semakin mengerucut menjadikanya unik. Keunikan juga dilihat dari kehidupan masyarakat Adat Wologai yang melaksanakan ritual dan upacara melalui wadah-wadah yang saling berhubungan dan mendukung dalam pemanfaatan ruang budaya dan ritual tersebut. Perwujudan pola ruang dalam ruang Kampung Adat Wologai memisahkan ruang-ruang sakral dengan ruang sebagai fungsi kegiatan masyarakat adat. Penataan ruang Kampung Adat Wologai sangatlah berkaitan erat dengan konsep kekerabatan yang ditandai dengan tiang batu yaitu Tubu Musu sebagai lambang persatuan untuk semua masyarakat adat. Konsep kekerabatan Kampung Adat Wologai dapat dilihat pada Gambar 17.

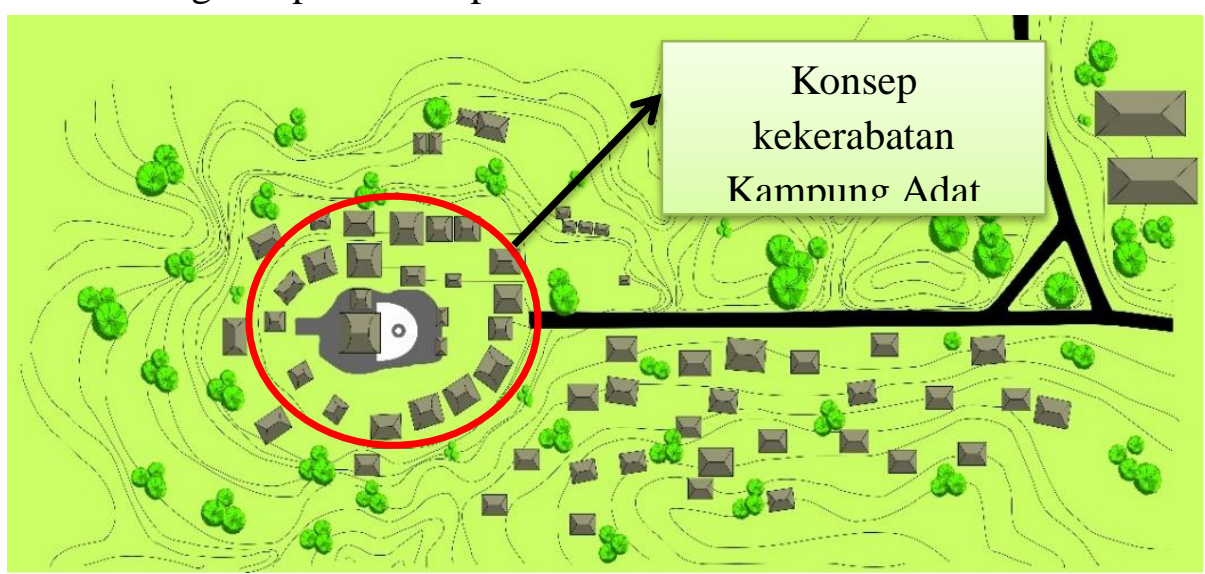

Gambar 17. Lokasi Kampung Adat Wologai

Sumber: Dimodifikasi dari Achmad (2014)

Kampung Adat Wologai dibuat berdasarkan konsep kekerabatan dan bertujuan untuk antisipasi masyarakat Wologai terhadap alam lingkunganya dan hubunganya dengan pencipta alam semesta yang dipercayai oleh masyarakat. Hal ini dapat dilihat dari acara ritual adat yang masih dilaksanakan sesuai dengan waktunya, dan dilakukan terus menerus oleh satu generasi ke generasi berikutnya. Konsep kekerabatan tersebut memiliki makna yaitu menjaga persatuan dan kesatuan, tetap menjalin persaudaraan dan kekeluargaan satu dengan yang lain antar sesama masyarakat. Konsep tersebut sangat dipegang teguh oleh masyarakat Kampung Adat Wologai dari dahulu sampai pada saat ini.

Konsep kekerabatan merupakan konsep lokal yang secara turun-temurun dijaga dan ditanamkan oleh masyarakat Wologai sebagai suatu kekuatan untuk menjaga kampung dan juga menjaga hubungan masyarakat dengan leluhur yang sudah meninggal dan juga menjaga hubunganya dengan sang pencipta. Berdasarkan konsep kekerabatan untuk saling menjaga maka terbentuklah pola melingkar di Kampung Adat Wologai. Pola di Kampung Adat 
Wologai berbentuk melingkar dan berkarakteristik bertingkat-tingkat semakin ke atas semakin mengerucut. Pola melingkar Kampung Adat Wologai dapat dilihat pada Gambar 18.

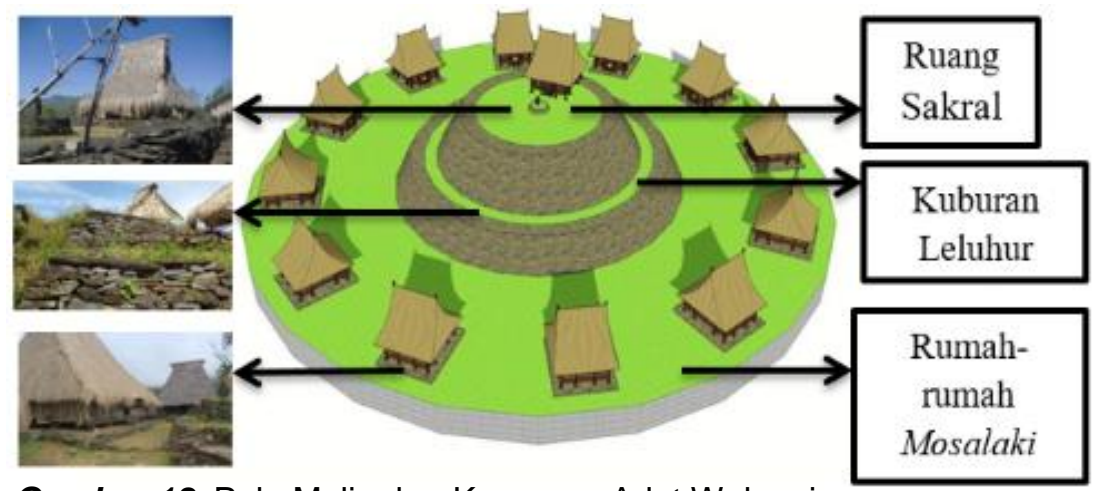

Gambar 18. Pola Melingkar Kampung Adat Wologai

Sumber: Hasil Analisis, 2018

Menurut Norberg-Schulz (1979) dalam suatu lingkungan tempat suci berfungsi sebagai pusat yang selanjutnya menjadi orientasi dan identifikasi bagi manusia, dan merupakan struktur ruang. Jadi, massa bangunan yang ada di Kampung Adat Wologai tidak sekadar mewadahi aktivitas manusia saja tapi juga dimaknai agar hidup selalu terkait dengan alam dengan penciptanya serta para leluhur.

Ruang sakral adalah ruang yang memiliki nilai kesucian yang dipercayai oleh masyarakat Kampung Adat Wologai. Ruang sakral terdiri dari Keda (rumah induk yang berfungsi sebagai tempat musyawarah dan berkumpulnya para Mosalaki), Kanga (tumpukan batu yang melingkari Tubu Musu yang berfungsi sebagai tempat pelaksanaan tarian adat gawi), dan Tubu Musu (tiang batu yang menghadap ke atas langit yang berfungsi sebagai persembahan kepada sang pencipta).

Kuburan leluhur merupakan kuburan dari leluhur masyarakat Kampung Adat Wologai, dimana kuburan tersebut melingkari ruang sakral yang berada di tengah kampung. Para leluhur dikuburkan dengan menggunakan batuan megalitik dan melingkari ruang sakral agar bersatu dengan sang pencipta dan berdekatan dengan rumah-rumah adat dengan maksud agar para leluhur yang sudah meninggal ikut menjaga kampung dan masyarakat Wologai.

Rumah-rumah adat yang melingkari kuburan leluhur dan ruang sakral merupakan rumahrumah para Mosalaki yang mendiami Kampung Adat Wologai. Rumah-rumah tersebut menghadap ruang terbuka sebagai bentuk penghormatan kepada leluhur dan kepada sang pencipta. Untuk lebih jelas terkait posisi rumah Mosalaki, dijelaskan sebagai berikut: lingkaran merah yaitu rumah Mosalaki Pu'u (Mosalaki utama), lingkaran kuning yaitu rumah Mosalaki Ria Bewa (juru bicara Mosalaki Kampung Adat Wologai), dan lingkaran biru yaitu ruang sakral yang terdiri dari Keda, Tubu Musu dan Kanga. Posisi rumah pemimpin Mosalaki tertinggi yaitu Mosalaki Pu'u dan Mosalaki Ria Bewa di Kampung Adat Wologai dapat dilihat pada Gambar 19. 


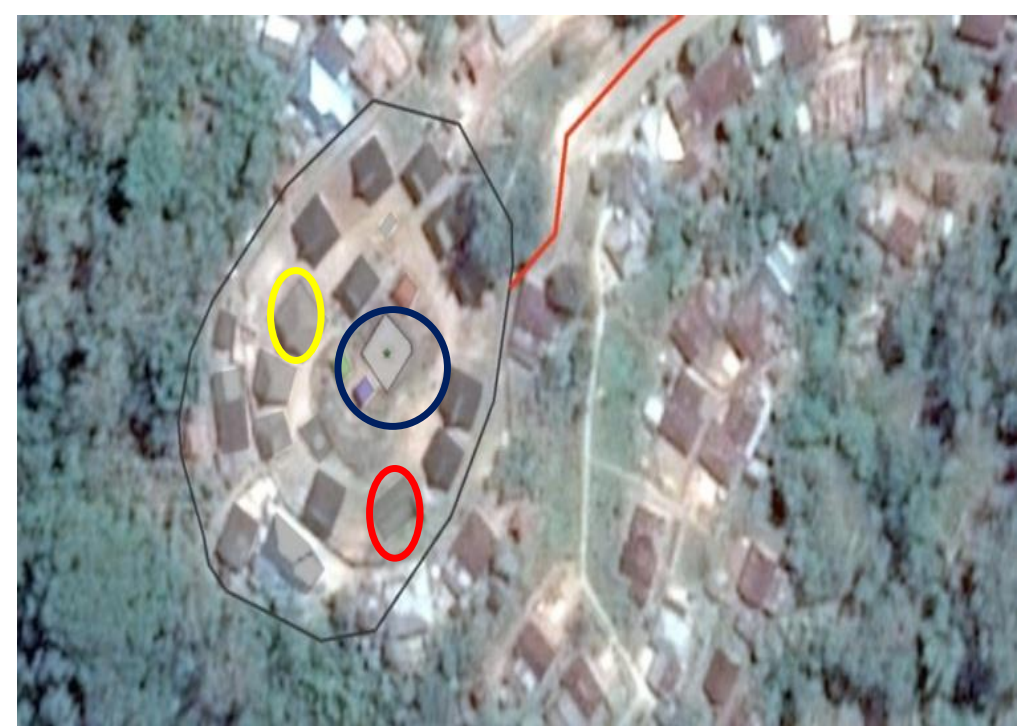

Gambar 19. Posisi Rumah Pemimpin Mosalaki tertinggi di Kampung Adat Wologai

\section{Kesimpulan}

Orientasi perkampungan Adat Wologai menghadap ke Gunung Lepembusu, disebabkan oleh karena asal usul leluhur masyarakat Wologai dari Gunung Lepembusu dan juga karena di Gunung Lepembusu adalah kampung asal atau kampung pertama Wologai (Wologai Nua $\left.P u^{\prime} u\right)$. Hubungan kepercayaan gunung dan laut dengan kampung terlihat pada garis linear dimana puse atau pusat merupakan Kampung Adat Wologai.

Struktur garis linear pada kepercayaan gunung, kampung dan laut diibaratkan seperti seorang manusia. Pengertian tersebut ada pada ungkapan adat yaitu uzhu du mutu hai kenda ia yang artinya kepala manusia bersandar di Gunung Lepembusu, dan kaki bertumpuk pada laut dan di tengah-tengah antara gunung dan laut adalah tubuh manusia yaitu Kampung Adat Wologai. Ungkapan adat tersebut memiliki makna bahwa manusia yang sudah meninggal dikuburkan bagian kepalanya harus menghadap gunung dan kakinya menghadap laut

Upacara dan ritual adat yang masih asli dan terus-menerus dilakukan oleh masyarakat Adat Wologai dan pola penataan ruang Kampung Adat Wologai yang berbentuk melingkar serta memiliki karakteristik bertingkat-tingkat, menjadi sebuah fenomena yang unik untuk dieksplor. Pola tata ruang Kampung Adat Wologai berbentuk melingkar dan dibuat berdasarkan hubungan kekerabatan dan bertujuan untuk antisipasi masyarakat Wologai terhadap alam lingkunganya dan hubunganya dengan pencipta alam semesta yang dipercayai.

Di dalam Kampung Adat Wologai terdapat Tubu Musu sebagai lambang persatuan dalam Kampung Adat Wologai dan juga memiliki makna yaitu menjaga persatuan dan kesatuan antar masyarakat. Masyarakat harus hidup saling menghormati dan menghargai dalam komunitas adat Wologai. Tatanan dalam ruang Kampung Adat Wologai memiliki elemenelemen penyusunanya. Elemen-elemen penyusunan ruang Kampung Adat Wologai terdiri dari lima elemen berupa, Sa'O (rumah Mosalaki), Keda (rumah induk tempat bermusyawarah), Kanga (areal lingkaran yang tersusun dari batu), Tubu musu (batu yang 
berdiri tegak menghadap ke atas langit dan lele lako yang merupakan pohon beringin yang berada di bagian depan pintu masuk menuju Kampung Adat Wologai.

\section{Daftar Pustaka}

Achmad, Z. (2014). Permodelan Ruang Budaya Pada Acara penerimaan Tamu di Kampung Adat Wologai Desa Wologai Tengah, Kabupaten Ende, NTT. April 2014. Retrieved from https://www.academia.edu/10222023

Achmad, Z. (2017). Tipologi Bentuk dan Pola Tata Massa Permukiman Arsitektur Rumah Suku Lio Desa Wologai Tengah, Kabupaten Ende, NTT. April 2017. Retrieved from https://www.academia.edu/11684730

Allsopp, B. (1977). A Modern Theory of Architecture. Jakarta: Dian Rakyat.

Gunawan, I. (2015). Metode Penelitian Kualitatif: Teori dan Praktik. Jakarta: PT .Bumi Aksara.

Lake, R. (2015). Wologai, Eksotisme Vernakular di Kaki Gunung Lepembusu. Nusa Tenggara Timur: Gita Kasih.

Norberg-Schulz, C. (1979). Genius Loci. New York: Electa/Rizolly.

Pemerintah Kabupaten Ende. (2015). Profil Pariwisata Kabupaten Ende. Ende: Dinas Kebudayaan dan Pariwisata. 